\title{
Surgical Treatment of Ascending Aortic Aneurysms by Means of Cardiopulmonary Bypass
}

\author{
Ken-ichi Asano, M.D., Masahiko Washio, M.D., Shoji Egughi, M.D., \\ Yoshifumi Sakurai, M.D., Isao Sakashita, M.D., Takao Irisawa, M.D., \\ Eiichiro Aoki, M.D., Masanori Terashima, M.D., Yoshimi Takeuchi, M.D., \\ Hideo Matsuzawa, M.D., Tetsunosuke Matsukawa, M.D., \\ Tatsuhiko Hirono, M.D., and Shigetaka Kasuya, M.D.
}

\begin{abstract}
SUMMARY
Four cases with ascending aortic aneurysm-two saccular aneurysms, one with dissecting aneurysm of DeBakey's type I and one with aneurysmal dilatation of the ascending aorta associated with aortic regurgitation-successfully operated upon by means of cardiopulmonary bypass, are presented, and the special considerations of surgery of these conditions are described.
\end{abstract}

\section{Additional Indexing Words :}

Ascending aortic aneurysm Cardiopulmonary bypass Coronary perfusion Carotid perfusion

QURGICAL treatment of the ascending aortic aneurysm is one of the most D difficult cardiovascular operations. The authors have experienced 4 surgical cases with ascending aortic aneurysms which conditions were different from each other. The purpose of this paper is to report the clinical results and to describe the methods of cardiopulmonary bypass applied to these patients, respectively.

\section{Ciase Reports}

Case 1. A 52-year-old woman had complained of shoulder and chest pain since 7 months ago, and she had undergone the exploratory thoracotomy under the diagnosis of the lung cancer one month before admission at the other hospital. Physically, aortic pulsations were palpable and systolic murmurs, Grade $2 / 6$, were audible at the 2nd and 3rd intercostal spaces along the right sternal border. Chest Xray films revealed an anterior mediastinal mass and angiocardiograms taken after injection of the contrast medium into the pulmonary artery demonstrated simultaneous opacification of both the ascending aorta and the tumor (Fig. 1, a, b).

Operation was performed on May 31, 1968. The aneurysm was approached through a median sternotomy and it adhered firmly to the right lung. The aneurysm

From the Department of Thoracic and Cardiovascular Surgery, Faculty of Medicine, University of Niigata, Niigata.

Received for publication July 16, 1969. 

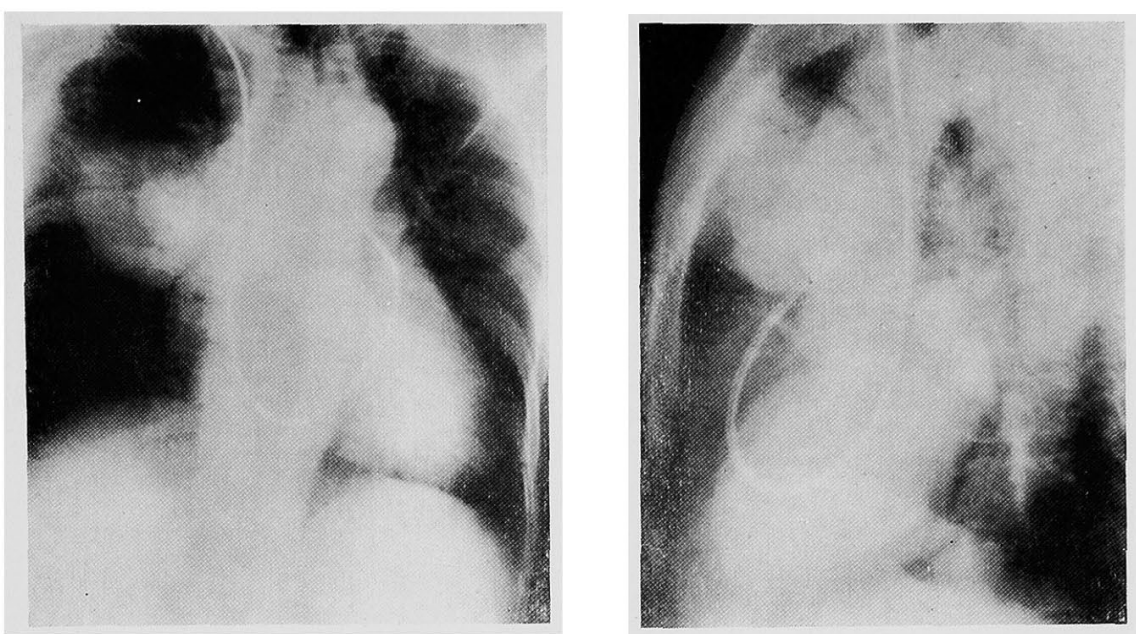

Fig. 1, a and b. Angiocardiograms of Case 1, taken after injection of contrast medium into the pulmonary artery.

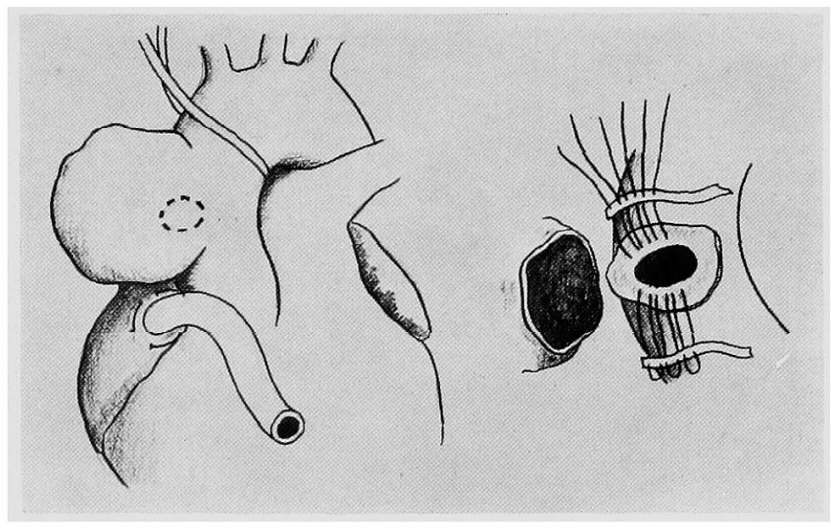

Fig. 2. Operative findings of Case 1.

was divided at its neck after clamping the aorta proximal to the innominate artery under cardiopulmonary bypass. The aortic opening was closed by several interrupted mattress sutures with teflon pledgets (Fig. 2). Coronary perfusion during aortic occlusion was not performed. After termination of bypass and neutralization of heparin by protamin sulfate, the aneurysmal wall was removed from the right lung. Postoperative course was uneventful.

Case 2. A 39-year-old man was suffered from severe chest pain and dyspnea two and a half years ago. He was again attacked by the same symptoms associated with abdominal pain 3 weeks before admission. Physically, the right radial and left femoral pulses were weak and the right femoral pulse was absent. The abdominal aortic aneurysm was also palpable left to the navel. On auscultation, systolic murmurs, Grade 2/6-3/6, were audible at the 2 nd intercostal space along the right sternal border. Chest X-ray films suggested the dissecting aneurysm of the thoracic aorta, and the retrograde aortography disclosed the dissecting aneurysm of the entire aorta of DeBakey's type I (Fig. 3, a, b). 


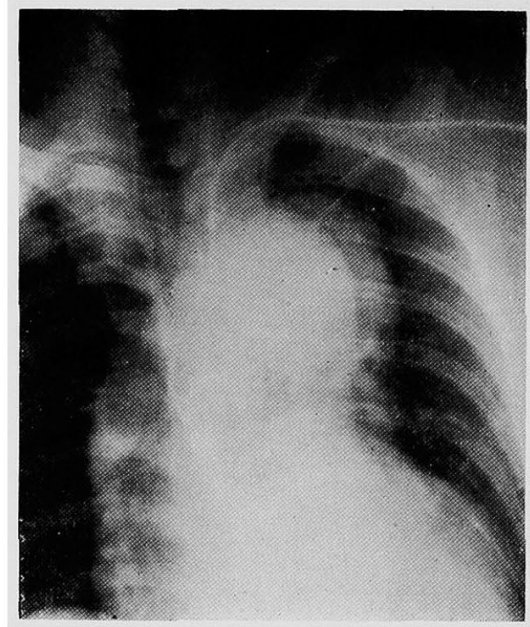

(a)

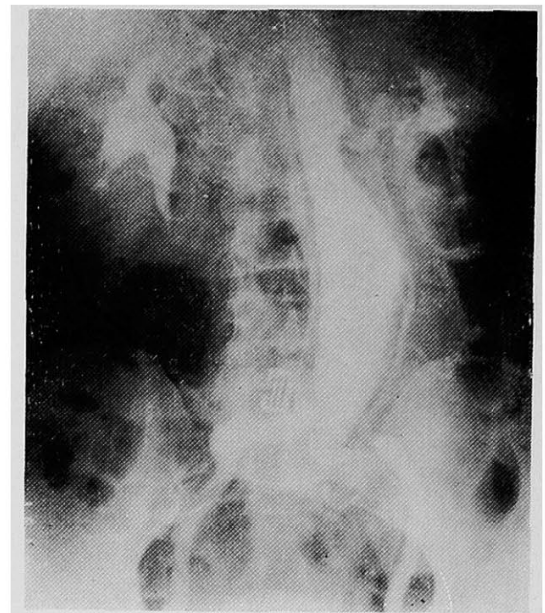

(b)

Fig. 3, a and b. Retrograde aortograms of Case 2. The aorta is dissected from the ascending portion to the bifurcation.

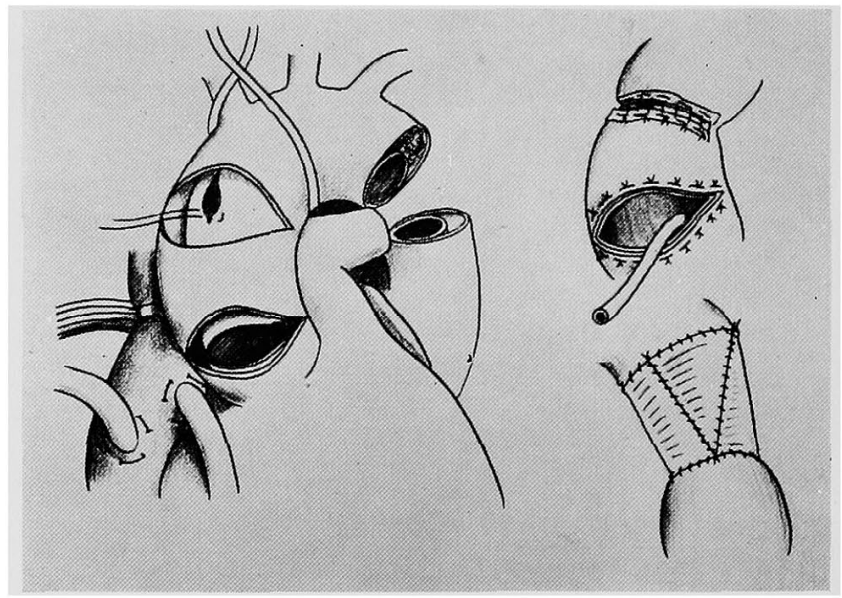

Fig. 4. Findings of the first and second operations of Case 2.

Operation was carried out on December 21, 1967. The aorta was explored by a median sternotomy and the intimal tear was found at the middle portion of the ascending aorta by probe-examination through the opening of the aortic root under cardiopulmonary bypass. After closure of the intimal tear through the second aortic incision and approximation of the dissecting lumen at each incised stumps, the proximal and distal incisions of the aorta were closed doubly by interrupted mattress sutures and running over-and-over sutures. Throughout this procedure, the left coronary perfusion was maintained at flow rate of $200 \mathrm{ml} . / \mathrm{min}$. (Fig. 4).

The postoperative course was smooth. However, because the back pain occasionally appeared and the shadow of the descending thoracic aorta was somehow enlarged in the chest X-ray films, "fenestration" was performed at the descending thoracic aorta just distal to the left subclavian artery by means of left heart bypass with flow rate of $1,300 \mathrm{ml}$./min. 2 months after the first surgery (Fig. 4). 


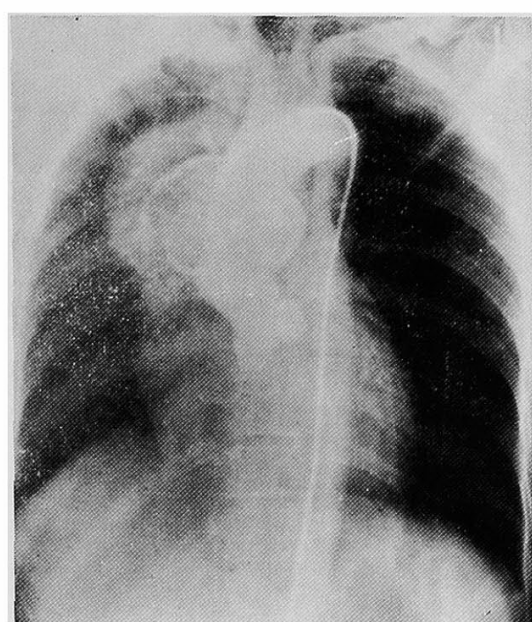

(a)

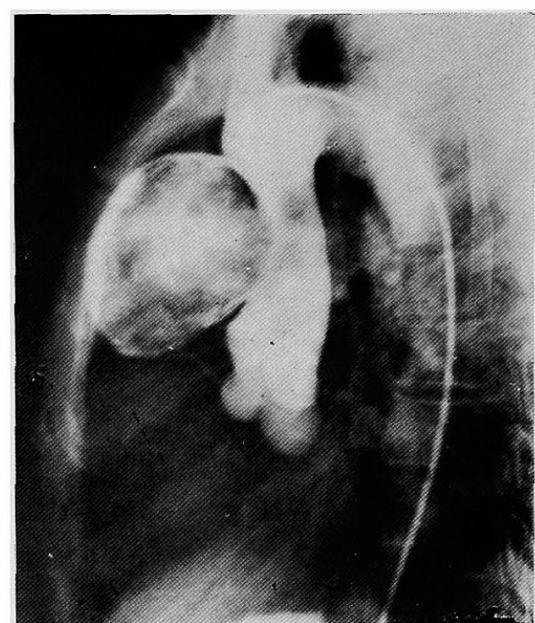

(b)

Fig. 5, a and b. Retrograde aortograms of Case 3. A calcified shellshaped aneurysm and another not-intensively opacified aneurysm are demonstrated.

The postoperative course was not eventful and the back pain subsided.

Case 3. A 36-year-old woman was admitted with complaints of dizziness, left hemiparesthesia and palpitation of one year duration. Physical examinations revealed aortic pulsations and slight systolic murmurs, Grade 1/6, at the 2nd intercostal space along the right sternal border. Chest $\mathrm{X}$-ray films showed a calcified shell-shaped tumor at the anterior mediastinum and another larger and noncalcified mass enclosing the former at the right upper thorax. Retrograde aortograms demonstrated opacification of the former, but the contrast of the latter was not intensified (Fig. 5, a, b).

At operation on March 20, 1969, it was found that the upper margin of the calcified aneurysm was just proximal to the innominate artery and its lower margin adhered to the right atrium and ventricle. The superior vana cava and the right pulmonary artery were completely occluded by compression of the aneurysm. Under cardiopulmonary bypass, the calcified aneurysm was partially incised with knife and partially sheared with bone longeur after clamping the aorta just proximal to the innominate artery. Then, the ascending aorta was divided at the upper margin of the aneurysm after re-cross clamping of the aorta just distal to the left carotid artery. Two cannulas from the arterial line of the pump-oxygenator which were threaded through a woven teflon tube graft were introduced into the orifices of the innominate and left carotid arteries through the lumen of the opened ascending aorta. These cannulas were held in place by tapes placed externally around those vessels. A combined flow rate into both carotid arteries of $800 \mathrm{ml} . / \mathrm{min}$. was maintained (Fig. 6).

After completion of the anastomosis between the graft and the distal stump of the ascending aorta, these 2 cannulas were withdrawn. Another aortic clamp was placed onto the graft and the distal clamp was removed to allow cerebral perfusion from the distal aorta via the femoral artery in the usual manner during cardiopulmonary bypass. Then the proximal aorta was divided and the proximal anastomosis 


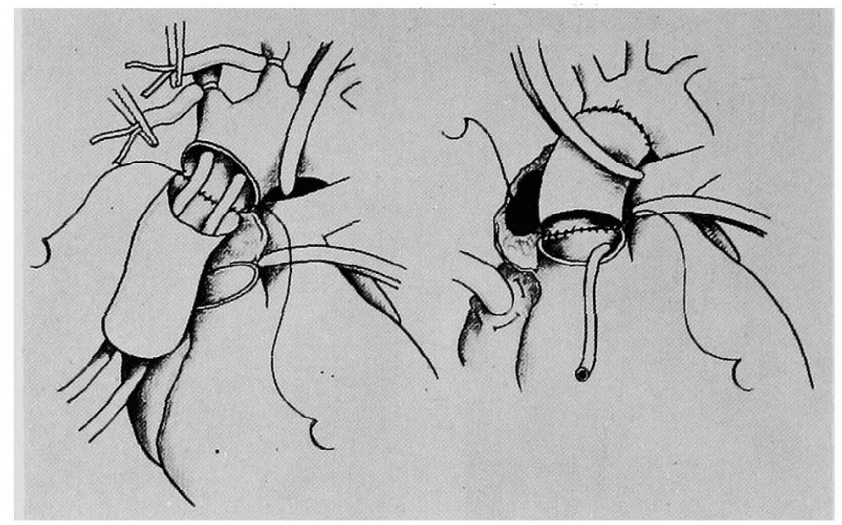

Fig. 6. Operative findings of Case 3. The left figure shows the distal anastomosis under carotid perfusion, and the right shows the proximal anastomosis under coronary perfusion.

was performed. The coronary circulation was maintained by the left-sided coronary perfusion during this procedure (Fig. 6).

After the ascending aorta was reconstructed and cardiopulmonary bypass terminated, the residual wall of the calcified aneurysm was removed and the massive thrombus in another aneurysm, that is, the secondarily developed pseudoaneurysm was scraped out through the communication with the former. The postoperative course was uneventful.

Case 4. A 28-year-old man had complained of palpitation and anginal pain since 6 months ago. He had been manifested by typical signs of the Marfan's syndrome. On auscultation, diastolic murmurs, Grade 3/6, were audible maximally at the 2nd intercostal space along the left sternal border and radiated to the apex and there the Austin-Flint's murmurs, also, were heard. Chest X-ray films revealed the enlarged ascending aorta and left ventricle. Electrocardiograms showed left ventricular hypertrophy and ST-depression at the left precordial leads. Right heart catheterization did not demonstrate any shunt but the pulmonary artery systolic pressure elevated to $60 \mathrm{~mm} . \mathrm{Hg}$. Retrograde aortography disclosed the extremely dilated aortic annulus and aneurysmal dilatation of the ascending aorta associated with aortic regurgitation of Grade 3/4 (Fig. 7, a, b).

Operation was performed on May 27, 1969. The mediastinum was explored through a median sternotomy. The aortic root was dilated to $7 \mathrm{~cm}$. in diameter and the origin of the right coronary artery was dislocated cranially. Under cardiopulmonary bypass, the aneurysmal aorta was resected taking care not to injury coronary arteries. The aortic wall was thin, the annulus was extremely dilated and aortic cusps were fragile and involuted. After valvulectomy, a 13-A Starr-Edwards ballvalve was inserted by 14 mattress sutures thrusted from the external side of the aortic wall and 3 mattress sutures at the internal side. Accordingly, the dilated anuulus was constricted to the size of the suture-ring of the ball-valve. Then a woven teflon graft which distal part was widened in order to attach to the aortic root was sutured to both the proximal and distal stumps. Through these procedures, bilateral coronary perfusion was maintained at flow rate of $330 \mathrm{ml} . / \mathrm{min}$. (Fig. 8, a, b). The postoperative course was uneventful and smooth. 


\section{Methods of Cardiopulmonary Bypass}

The disc oxygenator was used in Cases 2 and 4, and the bubble disposable oxygenator was applied to others. The pump-oxygenator was conventionally primed with fresh heparinized blood diluted by Ringer's lactate solution, mannitol and sodium bicarbonate solutions.

An arterial cannula was introduced into the femoral artery in Cases 1, 3 and 4, but in Case 2 the axillary artery was used because perfusion from the lower extremity artery was anticipated to be disturbed by aortic dissection.

Total cardiopulmonary bypass was made by occlusion of both venae cavae in Cases 2 and 4, and by clamping the pulmonary artery in Cases 1 and 3. Flow rate was ranged from 33.3 to $64.3 \mathrm{ml} . / \mathrm{Kg}$. $/ \mathrm{min}$. under mild or moderate hypothermia from 29.2 to $32.2^{\circ} \mathrm{C}$ of the esophageal temperature.

Coronary perfusion was performed in Cases 2 and 3 in the left side only and in Case 4 bilaterally. Its duration was from 20 to $95 \mathrm{~min}$., and its flow rate was ranged from 150 to $330 \mathrm{ml} . / \mathrm{min}$. Resumption of heart beat after release of the aortic clamping was smooth in all including Case 1 without coronary perfusion. Carotid perfusion in Case 3 was as described above, and constant electroencephalographic monitoring was made through operation.

Duration of total cardiopulmonary bypass was from $32 \mathrm{~min}$. to $125 \mathrm{~min}$. At termination of bypass, arterial blood $\mathrm{pO}_{2}, \mathrm{pCO}_{2}$ and $\mathrm{pH}$ were measured, and the base deficit was corrected by administration of sodium bicarbonate solution. Extracorporeal circuits applied to these cases are diagrammatized in Fig. 9, and details of cardiopulmonary bypass are summarized in Table I.

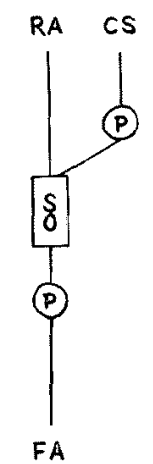

CASE 1

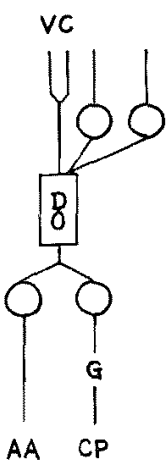

CASE 2

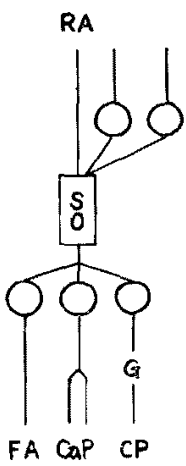

CASE 3

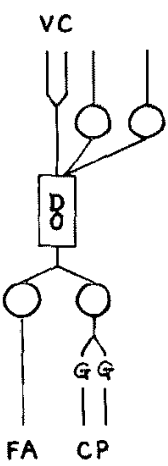

CASE 4

Fig. 9. Diagram of extracorporeal circuits.

AA: Axillary artery, CP: Coronary perfusion, CS: Coronary suction, CaP: Carotid perfusion, DO: Disc oxygenator (Pemco-Davila), FA: Femoral artery, G: "Gravity and overflow" system, RA: Right atrium, SO : Sheet oxygenator*

* Junken Company Inc., Higashimatsuyama, Saitama, Japan. 


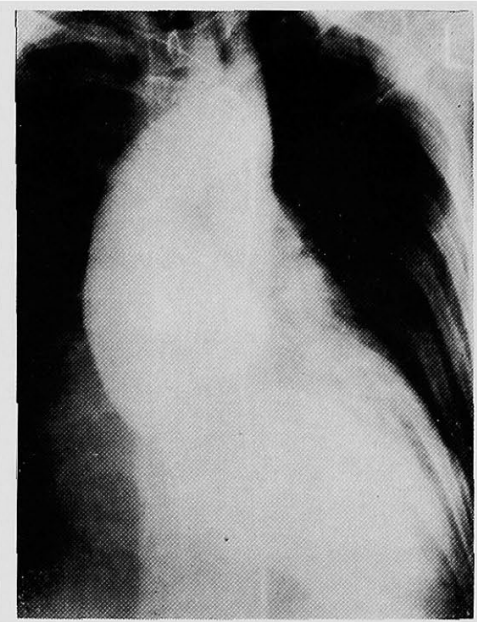

(a)

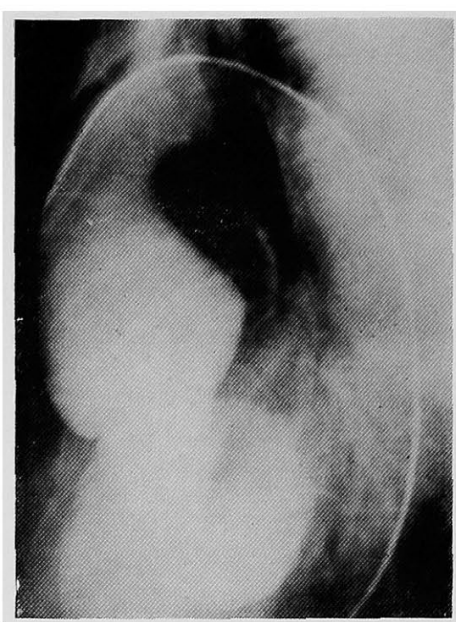

(b)

Fig. 7, a and b. Retrograde aortograms of Case 4. Extremely dilated annulus and aneurysmal dilatation of the ascending aorta with severe aortic regurgitation are demonstrated.

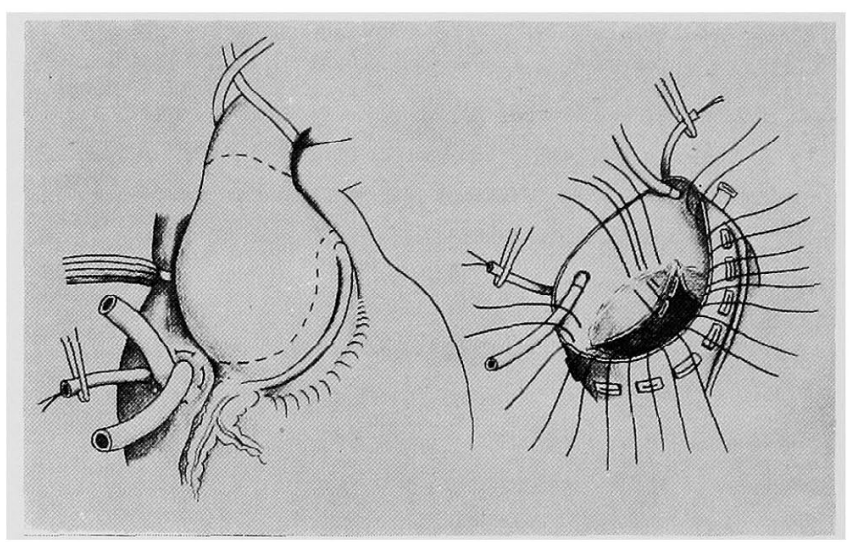

(a)

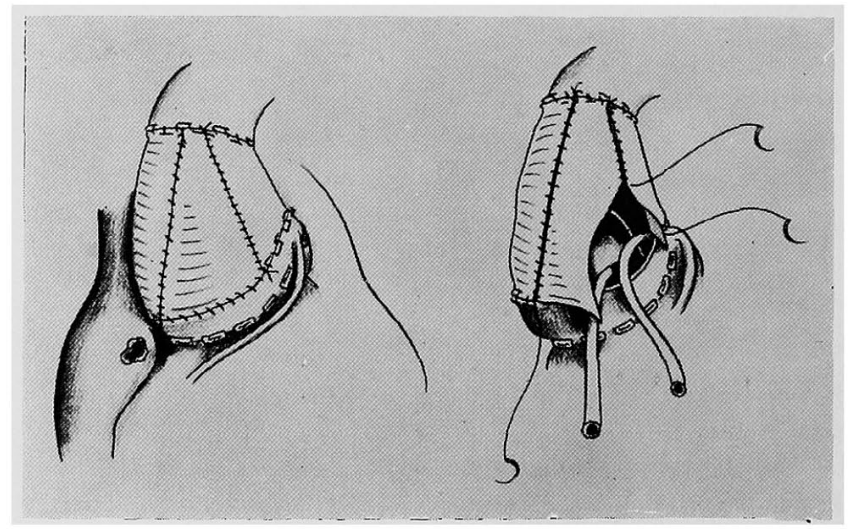

(b)

Fig. 8, a and b. Operative findings of Case 4. 
Table I. Data of Cardiopulmonary Bypass

\begin{tabular}{|c|c|c|c|c|c|c|c|c|}
\hline \multirow{2}{*}{ Case } & \multirow{2}{*}{$\begin{array}{l}\text { Rectal temp. } \\
\left({ }^{\circ} \mathrm{C}\right)\end{array}$} & \multirow{2}{*}{$\begin{array}{l}\text { Esophag. } \\
\text { temp. } \\
\left({ }^{\circ} \mathrm{C}\right)\end{array}$} & \multirow{2}{*}{$\begin{array}{c}\text { Body flow } \\
\text { (ml./Kg.) } \\
\text { min.) }\end{array}$} & \multicolumn{2}{|c|}{ Coron. perfusion } & \multicolumn{2}{|c|}{ Carotid perfusion } & \multirow{2}{*}{$\begin{array}{c}\text { Total } \\
\text { bypass } \\
\text { time (min.) }\end{array}$} \\
\hline & & & & $\min$. & $\mathrm{ml} / \mathrm{min}$ & $\min$ & $\mathrm{ml} / \mathrm{min}$ & \\
\hline 1 & 32.0 & 32.2 & $33.3-37.5$ & - & - & - & - & 32 \\
\hline 2 & 34.1 & 29.5 & $37-39$ & 52 & 200 & - & - & 76 \\
\hline 3 & 31.2 & 31.1 & 64.3 & 20 & 150 & 21 & 800 & 72 \\
\hline 4 & 30.3 & 29.0 & $51.7-58.6$ & 95 & 330 & - & - & 125 \\
\hline
\end{tabular}

\section{Comment}

Successful surgery of two saccular aneurysms, one dissecting aneurysm and one aneurysmal dilatation associated with aortic regurgitation by means of cardiopulmonary bypass was reported. Among these conditions, surgical treatment of saccular aneurysm of the ascending aorta does not always need the aid of cardiopulmonary bypass, and occasionally the aneurysm of this type can be removed by simply applying the vascular clamp to its neck. However, certain auxillary methods, especially to prevent myocardial and cerebral damages, are frequently required in actual practicc. One of them is the transient graft bypass reported by Coolcy and associates, ${ }^{1)}$ and the other is circulatory arrest under profound hypothermia induced by extracorporeal circulation. ${ }^{2)}$ However, because there are many disadvantages, for example, technical troubles in the former and time limitation of safe circulatory arrest in the latter, respectively, as described elsewhere, ${ }^{3)}$ cardiopulmonary bypass by pump-oxygenator with coronary and/or carotid perfusion appears to be the most universal auxillary method for surgical treatment of the ascending aortic aneurysm. But, the extracorporeal circuit to accomplish such types of perfusion is frequently more complicated like as illustrated in Fig. 9 than that in routine open-heart surgery.

In the past, postoperative bleeding following cardiopulmonary bypass had been experienced as a troublesome and occasionally fatal complication in some cases, but it is now usually rather well-controllable, if technique of aneurysmectomy, aortic suture method, selection of proper vascular grafts such as woven teflon tube graft, satisfactory achievement of blood coagulation and some devices for local hemostat such as application of oxicell-gauze are considered beforehand. Therefore, it is preferable to apply cardiopulmonary bypass with expectation of higher safety, even to surgery of saccular aneurysm as well as other types.

The carotid perfusion applied to Case 3 had been devised for surgery of 
aortic arch aneurysms by Bloodwell and associates. ${ }^{4)}$ In this case, the body flow rate was $65 \mathrm{ml} / \mathrm{Kg}$. $/ \mathrm{min}$. and the combined cerebral flow rate was $800 \mathrm{ml} . / \mathrm{min}$. The cerebral circulation appeared to be satisfactorily maintained by this flow rate and an early recovery from anesthesia was noted. No cerebral complications occurred after surgery.

Coronary perfusion was performed by means of "gravity and overflow" system previously described by the authors. ${ }^{5}$ ) Resumption of heart beat after release of aortic clamping was smooth and any myocardial damages or intractable arrhythmias were not encountered in every case.

\section{REFERENCES}

1. Cooley, D. A., Magaffey, D. E., and DeBakey, M. E.: Surg. Gynec. Obst. 101:667, 1955.

2. Dubost, C., Blondeau, P., and Piwnica, A. : J. Cardiovas, Surg. 3 : 286, 1962.

3. Asano, K., Sakurai, Y., Irisawa, T., and Kasuya, S.: (to be published).

4. Bloodwell, R. D., Hallman, G. L., and Cooley, D. A. : Arch. Surg. 92 : 558, 1966.

5. Eguchi, S., Matsuzawa, H., and Asano, K.: Surg. 64: 554, 1968. 